\title{
A systematic approach to evaluating the influence of demand side management resources on the interarea capacity benefit margin
}

\author{
Olatunji Obalowu Mohammed ${ }^{1}$, Mohd Wazir Mustafa ${ }^{2}$, Daw Saleh Sasi Mohammed ${ }^{3}$, Sani Salisu ${ }^{4}$, \\ Nabila Ahmad Rufa'i ${ }^{5}$ \\ ${ }^{1,2,3,4}$ School of Electrical Engineering, Universiti Teknologi Malaysia, Johor, Johor Bahru, Malaysia \\ ${ }^{1}$ Department of Electrical and Electronics Engineering, University of Ilorin, Ilorin, Kwara State, Nigeria \\ ${ }^{4}$ Department of Electrical Engineering, Ahmadu Bello University, Zaria, Nigeria \\ ${ }^{5}$ Department of Electrical Engineering, Bayero University Kano, Kano, Nigeria
}

\begin{tabular}{l} 
Article Info \\
\hline Article history: \\
Received Mar 29, 2019 \\
Revised May 27, 2019 \\
Accepted Jun 19, 2019 \\
\hline Keywords: \\
Capacity benefit margin \\
Demand side management \\
Generation reliability \\
Loss of load expectation
\end{tabular}

\begin{abstract}
Available transfer capability is an index to measure the security and economic viability of an interconnected system. However, to accurately determine this index, other associated parameters need to be accurately evaluated. One of these parameters is the capacity benefit margin (CBM). For efficient power generation reliability and sustainability, a certain amount of supply capacity is commonly reserved by utilities, which in most cases remain unused, to reduce the effect of generation outage. To minimize this unused reserve, utilities usually reserve a predetermined amount of tie-line capacity between interconnected areas to have access to external supply. This tie-line reserved for this purpose is termed as capacity benefit margin (CBM). In this paper a technique for computing CBM is used, the sensitivity of CBM support from other areas to the increase in load in one of the areas is investigated, and conclusively, demand side management is proposed to improve the quantification of CBM. The contribution of this work is the assessment of the CBMs support from other areas during a critical condition, using the flexibility of DSM technique. The modified 24-bus IEEE reliability test system is employed for the verification of the approach.
\end{abstract}

Copyright $@ 2019$ Institute of Advanced Engineering and Science. All rights reserved.

\section{Corresponding Author:}

Olatunji Obalowu Mohammed,

Department of Power System Engineering, School of Electrical Engineering,

Faculty of Engineering, Universiti Teknologi Malaysia,

81310 Johor Bahru. Malaysia.

Email: oomohammed2@live.utm.my

\section{INTRODUCTION}

Overestimation of available transfer capability (ATC) can lead to system instability which could result to cascading collapse [1-4] and underestimation of ATC value capable of causing underutilization of the power system resources which can subsequently lead to loss of capital as a result of ineffective marketing operations [5]. For example, the major blackout in the North-eastern United States and Ontario in August 2003 was a result of an overestimation of ATC [4, 6]. Therefore, the consequence of under/over-estimation of ATC has enormous adverse effects on the utility. Essentially, ATC is a measure of the transfer capability remaining in the physical transmission network over and above already committed uses, for future commercial activity [7]. The value of ATC is obtained by considering various parameters relating to power transfer capabilities: total transfer capability (TTC), transmission reliability margin (TRM) and capacity benefit margin $(\mathrm{CBM})$. TTC is the summation of all the parameters (ATC+TRM+Existing transmission 
commitment+CBM), TRM is the network margin reserved for system uncertainties while the CBM indicates the transfer capability margin reserved for accidental generation outages [7, 8].

In order to maintain electricity supply reliability and sustainability, power utilities usually keep some reserve capacity in case of an emergency power supply shortage due to generation outage or/and an unexpected increase in power demand. Because this reserve capacity commonly remains unused, the reserve capacities of interconnected areas can be reduced without degradation in generation reliability. This can be achieved by providing margin in the interconnected tie-lines for the purpose of power interchange between areas in an event of power shortage in any of the connected areas. This margin is termed as capacity benefit margin (CBM). It is determined either by deterministic or probabilistic approaches [9]. Accurate evaluation of CBM value is essential for available transfer capability (ATC) determination. Over/under-estimation of $\mathrm{CBM}$ value can leads to inaccuracy of ATC results, which can respectively lead to ineffective utilization of transmission system facilities and sudden generation deficiency in case of unexpected generator outages $[4,10]$. The CBMs of the interconnected areas are usually evaluated by using the reliability index, loss of load expectation (LOLE). The LOLE is evaluated using the cumulative probability of the least capacity outage that can result in loss of load due to insufficient generation for a given hourly peak load.

The LOLE is the average number of days or hours in a given period (usually one year) in which there is a loss of load i.e. the daily peak load or hourly load is expected to exceed the available generating capacity [11]. The value of LOLE authorized by the Mid-Atlantic Area Council (MAAC) is presently set at 1 day per 10 years (assumed to be 2.4 hours/year) as stipulated in the MAAC Reliability Principles and Standards [12]. If the LOLE index of an area in an interconnected system is higher than the specified value (2.4 hours/year), the area needs to improve its generation reliability by importing power from external areas to meet the generation reliability requirement. However, if the area LOLE is less than the specified value, the area is rich in generation capacity and it has the ability to export power to support other areas facing power deficiency.

For more than a decade, various techniques have been proposed to evaluate CBM [9, 13-19]. The simple technique used to calculate the CBM for interconnected areas is established by using trial and error [9], by predefining 5\% of the maximum transfer capability [20] or using an assumption of taking CBM as zero [21, 22]. Sun et al. [15] proposed an exponential analytic model (EAM) to evaluate multi-area generation reliability and sequential quadratic programming (SQP) is applied to find the CBM value considering the loss of load probability (LOLP) criterion. Monte Carlo simulation (MCS) and differential evolution (DE) is employed in [16] to determine the reliability index (LOLE) and CBM respectively. Othman et al. [13] employed evolutionary programming (EP) and the cumulative probability of generation outage to determine CBM and LOLE respectively. Particle swarm optimization (PSO) is used in [17, 18] to optimize the three different objectives formulated for the evaluation of the CBM, the cumulative probability method is also employed to evaluate LOLE. The first objective is to minimize the total LOLE of the interconnected areas, the second objective is to minimize the deviation of the LOLE of the supporting areas from their base case value and the third objective is to minimize the CBM of the interconnected areas. This is to provide multiple options for the market participants to select from the various options based on their first priority. The effect of wind power generation is incorporated in [18]. A Pareto-based evolutionary programming method was employed in [14] to determine the CBM of the interconnected areas simultaneously. However, most of these previous works use the LOLE criterion for the CBM evaluation, the LOLE is evaluated by using the area peak load demand and the reserve capacity. The system peak demand usually occurs within a few weeks in a year, therefore the long period of off-peak demand is not efficiently accounted for in the LOLE evaluation. Therefore, the reliability of the areas can be improved by using demand side management (DSM) activity to peak-shaved the load demand during the on-peak period and valley filled with the DSM resources during the off-peak period.

In this paper, a probabilistic approach is used to compute LOLE of each area for reliability assessment and a conventional method of computing interarea tie-line CBM is employed, the sensitivity of other areas' supply reliability to the change in load of one area is investigated, and finally DSM is proposed to improve interarea generation reliability and tie-line CBM. The modified 24 bus IEEE reliability test system is employed for the verification of the approach.

\section{RESEARCH METHOD}

In this section, LOLE computation using probabilities of capacity outages [23], CBM evaluation procedures, the sensitivity of reliability index to power exchange and DSM techniques, are discussed. 


\subsection{Probabilities of capacity outages}

The capacity outage probabilities are commonly employed to compute LOLE. Capacity outage probabilities of systems with identical generating units can be simply calculated by employing binomial distribution [23]. However, it is impractical to use binomial distribution for practical systems because practical systems contain non-identical generating units. Hence, the equivalent assisting unit technique is employed to compute the probabilities of the capacity outages of various units. This method is robust and uses a repetitive approach in which the units are sequentially added to give the complete representation of the probability of capacity outage [23]. The individual unit capacity outage probability can be obtained using (1).

$$
P_{I}\left(C_{s}\right)=\frac{n !}{s !(n-s) !} U^{s} A^{n-s}
$$

where, $P_{I}\left(C_{s}\right)$ : Capacity outage probability of the individual unit at state $s, s$ : number of state for the capacity outage, $n$ : the total number of states, A: system availability, $\mathrm{U}$ : system unavailability or forced outage rate (FOR).

\subsection{Computation of the lole and cbm evaluation}

LOLE shows the expected risk of loss of load for a particular period under study, it indicates system supply reliability and it is employed for the determination of CBM required for each area in an interconnected system. It can be calculated using (2), which is the summation of all the capacity outage probability that result in a capacity deficiency for a given forecasted demand at hour $\mathrm{h}$.

$$
L O L E=\sum_{h=1}^{N_{K}} P_{I}\left(C_{h}<D_{h}\right)(h / y r)
$$

where, $N_{K}$ : the total number of hours considered, h: hours, $C_{h}$ : available capacity at hour h, $D_{h}$ : forecasted demand at hour h, $P_{I}\left(C_{h}<D_{h}\right)$ : the probability of outage at the moment in which there is a risk of loss of load. The procedure for CBM evaluation is as follows;

a. Following the determination of the available generation of all the interconnected areas and the peak demand of each area, the base case LOLE is computed. Any area with LOLE above the specified value $(2.4 \mathrm{hr} /$ year) indicates that in an event of generation outage, that particular area will experience loss of load. Therefore it needs an additional external generation from other interconnected areas whose LOLE are below the specified value. The areas with LOLE less than $2.4 \mathrm{hr} /$ year are generation rich areas in which in an event of generation outage they will be able to serve their local loads and in addition support other areas. In this work, the area with LOLE above $2.4 \mathrm{hr} /$ year is termed as deficient area while the area with LOLE below $2.4 \mathrm{hr} /$ year is termed as generation-rich area.

b. Improve the generation capacity of the deficient area until its LOLE is less than $2.4 \mathrm{hr} / \mathrm{year}$ by importing power from other areas in incremental steps in inverse proportion to their LOLE, i.e. more power will be exported from the area with lowest LOLE. After the improvement, the LOLE of every area is recalculated if any area has LOLE above $2.4 \mathrm{hr} /$ year, then its generation capacity is improved by importing power to the area to bring down the LOLE to the specified value.

\subsection{Sensitivity of lole of areas to a change in power in one area}

In an interconnected system, where power interchange is used to alleviate the supply shortage among areas, a change in power in one of the areas influences the LOLE of other areas and vice versa [15]. Therefore, the application of DSM in one area can influence the supply reliability of other areas.

\subsection{Demand side management}

The DSM technique is an efficient method which incorporates the economic benefit with system reliability [24]. The use of DSM resources will improve reliability and mitigate network congestion [25]. In this work, the basics of DSM techniques which are peak clipping and valley filling are employed to enhance the generation reliability thereby improving the LOLE. The step involved in DSM application is as follows;

a. The peak load (usually within one week to three weeks) from the chronological load curve is extracted.

b. The extracted peak load is converted to the load duration curve (LDC) for the probabilistic simulation of DSM as the generating unit [26].

c. The peak clipping action gives a pre-specified percentage of the peak load i.e. the original peak load from the chronological load curve has been reduced by a certain percentage to give the pre-specified value. 
d. The pre-specified value will be used to replace the original peak load in the chronological load curve within the period in which it was extracted resulting in a modified chronological load curve having a reduced peak load.

e. The modified three weeks load model will be incorporated back to the one year chronological load model.

f. The new peak load in the whole system (one year) will now be used for the computation of LOLE.

g. During the off-peak period, the same amount of energy is refilled back into the system load but at a different period of time.

In the modified chronological load model (MCLM), the peak load is restricted to a pre-specified. The peak clipping and valley filling can be modelled using (3) [27], where $\mathrm{P}_{\mathrm{s}}$ is pre-specified peak load of the system which was obtained by the activities of the DSM.

$$
\begin{aligned}
& \bar{L}_{M}(t)=\left\{\begin{array}{c}
P_{s} \\
L_{M}(t)+K
\end{array} \quad t \in \psi=\left(t_{1}, t_{2}\right)\right. \\
& K=b\left[\frac{\sum_{t \in \tau} L_{M}(t)-P_{s}}{h}\right]
\end{aligned}
$$

where, $L_{M}(t)$ is the original load model, $\bar{L}_{M}(t)$ is the MCLM, $\psi$ is the off-peak period during which the clipped energy is refilled, $t_{1}, t_{2}$ represents the interval during which the energy is refilled, $\tau$ is the set of onpeak hours during which the energy is reduced, $\mathrm{K}$ is the energy refilled at each hour of $\psi, b$ is the fraction of the clipped that is recovered during off-peak hours, it actually depends on the customer demand in the offpeak hours, $\mathrm{h}$ is the number of off-peak hours in $\psi[25,27]$. Finally, the MCLM will be used in the LOLE computation, and this will subsequently enhance both the system reliability and the economic operation in an interconnected power system.

\section{DETAILS OF THE TEST SYSTEM}

Modified three areas IEEE 24-bus RTS data [9] is employed for the implementation of the proposed method. The complete data for the system can be found in [28, 29]. The details of the three areas are highlighted in Table 1. Four units (1x400 MW, 3x155 MW) were added to Area 1 (A1) which make the generation to increase from $1170 \mathrm{MW}$ to $2035 \mathrm{MW}$, one unit (1x197 MW) was added to Area 2 (A2) resulting in generation in A2 to increase from $1551 \mathrm{MW}$ to $1748 \mathrm{MW}$ and one unit (1x100 MW) was also added to Area 3 (A3) which increases its generation from $684 \mathrm{MW}$ to $784 \mathrm{MW}$. Their margin increases from $45 \mathrm{MW}$ to $910 \mathrm{MW}, 410 \mathrm{MW}$ to $607 \mathrm{MW}$ and $100 \mathrm{MW}$ to $200 \mathrm{MW}$ respectively as shown in Table 1 . The three area system is as shown in Figure 1.

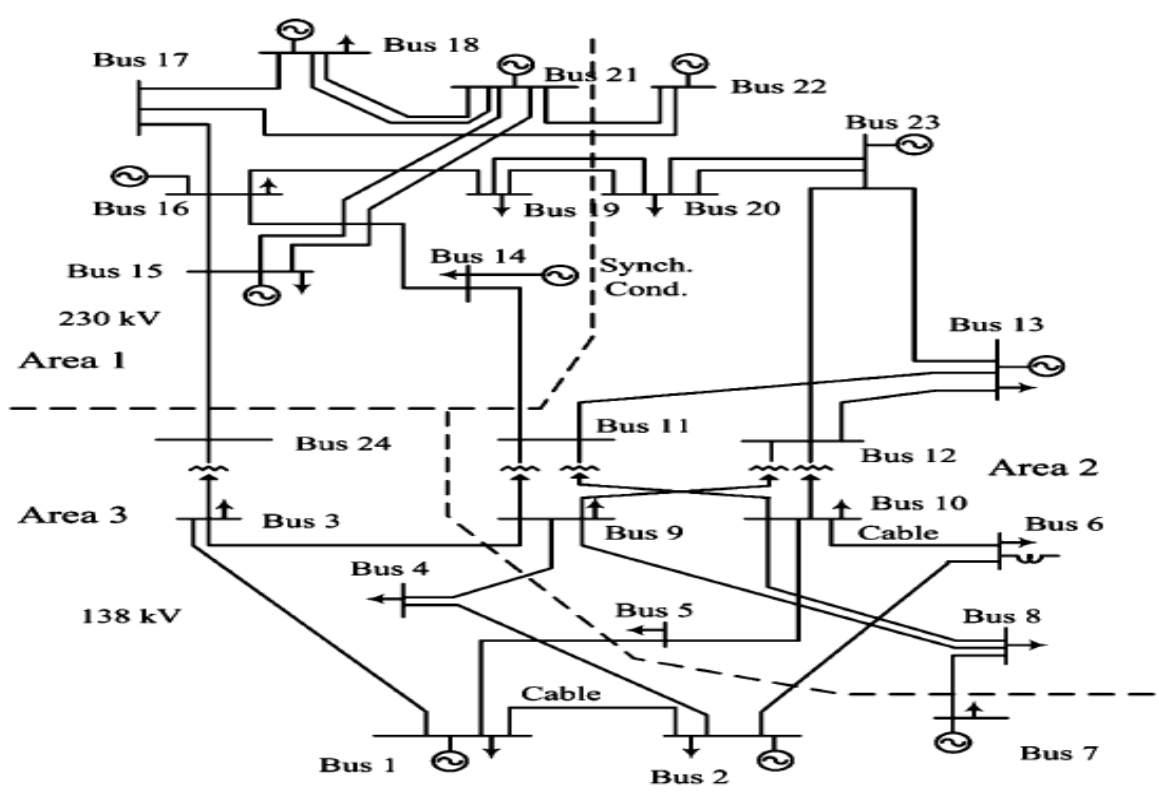

Figure 1. Modified IEEE 24-bus system 
Table 1. Details of the IEEE 24-bus three area RTS

\begin{tabular}{|c|c|c|c|c|c|c|}
\hline Area & Bus & $\begin{array}{l}\text { Initial Generation } \\
\text { (MW) }\end{array}$ & $\begin{array}{c}\text { Modified } \\
\text { Generation } \\
(\mathrm{MW})\end{array}$ & Load (MW) & $\begin{array}{c}\text { Initial } \\
\text { Margin } \\
(\mathrm{MW})\end{array}$ & $\begin{array}{c}\text { Modified } \\
\text { Margin (MW) }\end{array}$ \\
\hline 1 & $\begin{array}{c}14,15,16,17,18,19 \\
21,24\end{array}$ & 1170 & 2035 & 1125 & 45 & 910 \\
\hline 2 & $\begin{array}{c}5,6,8,9,10,11,12 \\
13,20,22,23\end{array}$ & 1551 & 1748 & 1141 & 410 & 607 \\
\hline 3 & $1,2,3,4,7,24$ & 684 & 784 & 584 & 100 & 200 \\
\hline
\end{tabular}

\section{RESULTS AND DISCUSSIONS}

At the base case, after the modification of system generation, the total generation of A1 is 2035 MW, A2 is $1748 \mathrm{MW}$ and A3 is $784 \mathrm{MW}$ as shown in Table 1, and their respective LOLEs are 4.776 hours/year, 0.6375 hours/year and 0.6913 hours/year as shown in Table 2. It can be seen that the LOLE of A1 is above 2.4 hours/year, and the LOLE of A2 and A3 are below 2.4 hours/year. This indicates that A1 is a deficient area and it requires external power generation to meet the generation reliability requirement in case of generator outage, whereas A2 and A3 have the reserve capacity to support A1. Therefore, A2 and A3 need to transfer power to A1 in order to compensate for the deficiency. The two generation-rich areas improve the generation capacity of A1 by exporting power to A1 until its LOLE is lower than 2.4 hours/year as shown in Table 3. Consequently, the CBM of A2 and A3 become -88 MW and -33 MW respectively. Hence, the combine supports from the two supporting areas results in $121 \mathrm{MW}$ value of CBM for A1, as the required CBM to compensate for its deficiency. The generation capacity of all areas are therefore updated to 2156 MW, $1660 \mathrm{MW}$ and $751 \mathrm{MW}$ for A1, A2 and A3 respectively. The negative sign of the CBM in A2 and A3 shows that power is injected into an external area.

Table 2. The results of LOLEs of all areas for the

\begin{tabular}{cccc}
\multicolumn{3}{c}{ base case } \\
\hline Area & Gen $(\mathrm{MW})$ & Load $(\mathrm{MW})$ & LOLE (hours/year) \\
\hline 1 & 2035 & 1125 & 4.7760 \\
2 & 1748 & 1141 & 0.6375 \\
3 & 784 & 584 & 0.6913 \\
\hline
\end{tabular}

Table 3. The LOLE and CBM results by updating the generation capacity of the areas

\begin{tabular}{cccc}
\hline Area & Gen $(\mathrm{MW})$ & CBM & LOLE (hours/year) \\
\hline 1 & 2156 & 121 & 2.3972 \\
2 & 1660 & -86 & 1.3943 \\
3 & 751 & -35 & 1.3569 \\
\hline
\end{tabular}

\subsection{Sensitivity of the increase in load in area 2 to change in lole and cbm of all areas}

It can be seen from Figure 2 that a successive increase in load in A2, leads to decrease in capacity support from the area from $86 \mathrm{MW}$ to $60 \mathrm{MW}$ after which its LOLE value is violated, while the support from A3 keep increasing from $35 \mathrm{MW}$ to $57 \mathrm{MW}$ after which its LOLE is violated, hence there is continuous degradation in the supply reliability in all the areas until it reaches a point where the LOLE in A2 is violated (LOLE>2.4 hour/year) as can be seen in Figure 3. Further increase in load in A2 leads to the violation of LOLE in all the areas. The increase in load from $1211 \mathrm{MW}$ to $1221 \mathrm{MW}$, causes $4 \mathrm{MW}$ decrease in the contribution to A1, this $4 \mathrm{MW}$ could not be met by two areas (A2 and A3) and $100 \mathrm{MW}$ is not enough for generation reliability in A1 and therefore the LOLE of areas are violated. In this critical condition, it is unrealistic to build another generating unit to support the deficiency because of the huge financial implications involved. If the situation required $50 \%$ of the peak load, it is reasonable to build more generating units, however, only $4 \mathrm{MW}$ capacity is required to support the inadequacy. The most economical way to solve the problem is by employing the activities of DSM in A2. A2 is used as a case study because it contains renewable energy (hydro units) which is usually not fully utilized [26]. 


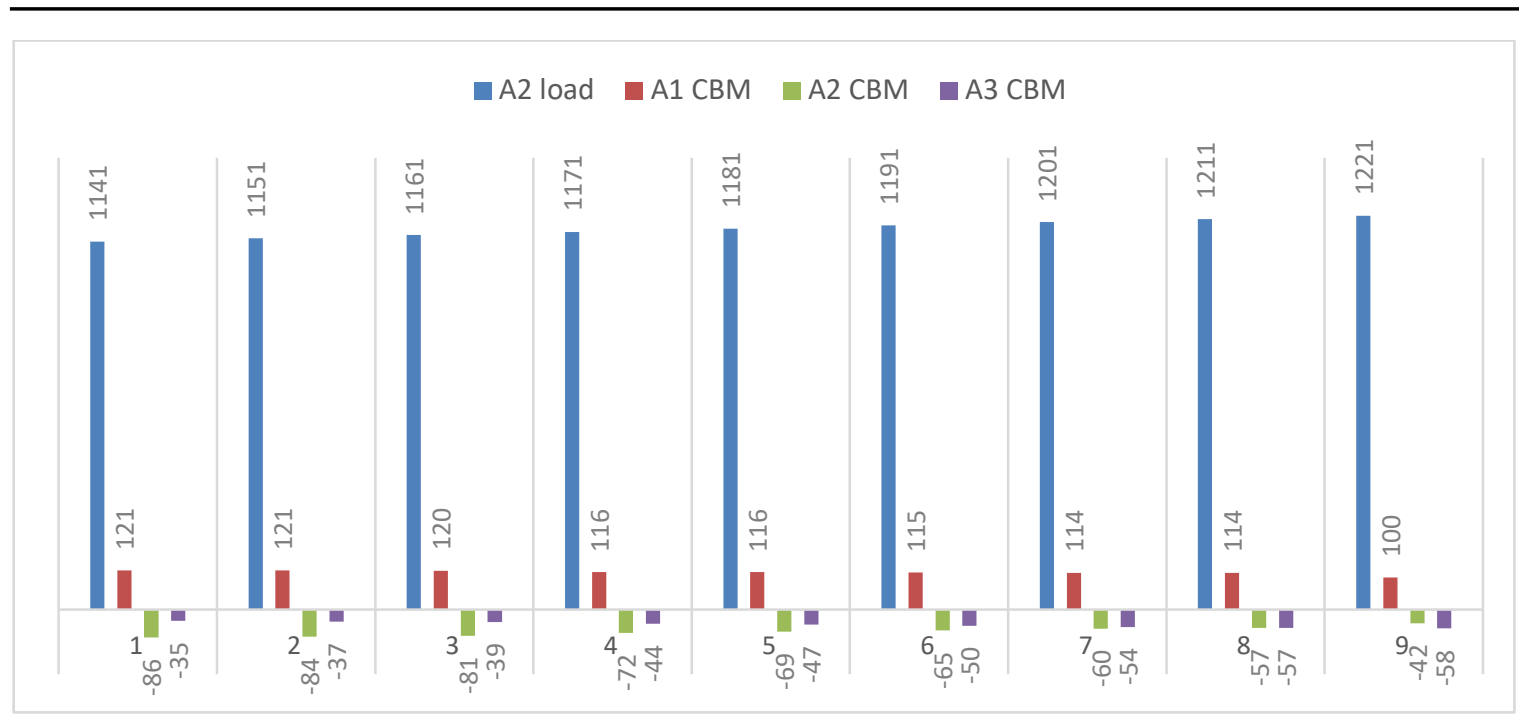

Figure 2. Effect of increase in load in area 2 on the CBM of all areas

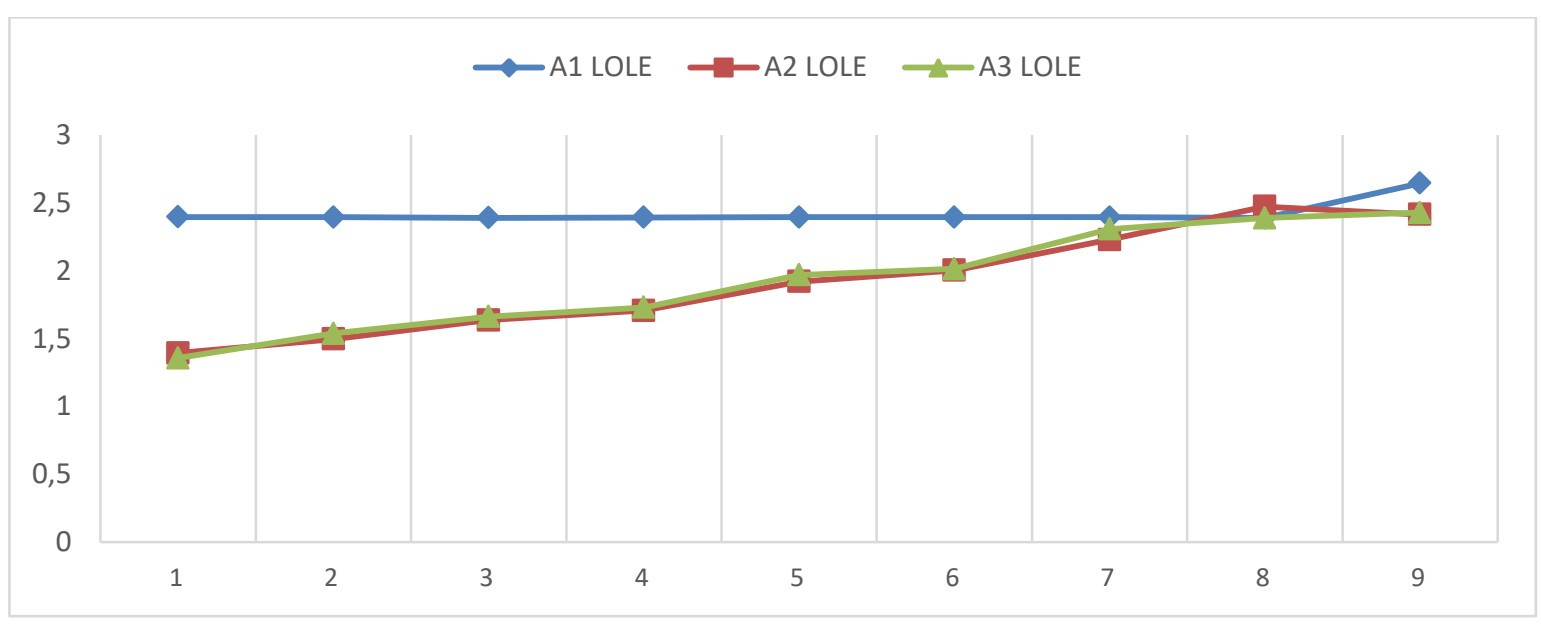

Figure 3. Effect of increase in load in area 2 on the LOLE of all areas

\subsection{The results of demand side management implementation}

In this work, the DSM activities are performed in A2. The renewable energy units are employed to peak-clipped the peak loads above the specified value of $1142.5 \mathrm{MW}$. The last three weeks of the year is selected for the DSM implementation and a total of $14835 \mathrm{MWh}$ energy is clipped during the on-peak hours and the same amount of energy is filled during the off-peak hours. The specified value is $93.6 \%$ of the peak demand (1221 MW) in A2, therefore, the peak demand within the three weeks is $93.6 \%$ of the peak demand. However, the LOLE computation will scan through the whole year and pick up the most peak load in the system which is $94.2 \%$ in week 49 [28], and this is equivalent to $1150.182 \mathrm{MW}$. The result of the DSM actions on the chronological load model for the three weeks (504 hours) is depicted in Figure 4. The influence of the DSM actions can be seen from Figure 5 and 6, the system load has improved the interarea CBM and the LOLE of every area. The LOLEs of A2 and A3 are remarkably reduced, and the CBM contribution from A2 has doubled (from $42 \mathrm{MW}$ to $84 \mathrm{MW}$ ). As described in section 4.1, the continuous increase in A2 demand results in reliability and CBM degradation such that the LOLE of all areas have been violated. However, due to the peak clipping action of the DSM, the LOLE and CBM of all areas are improved. 


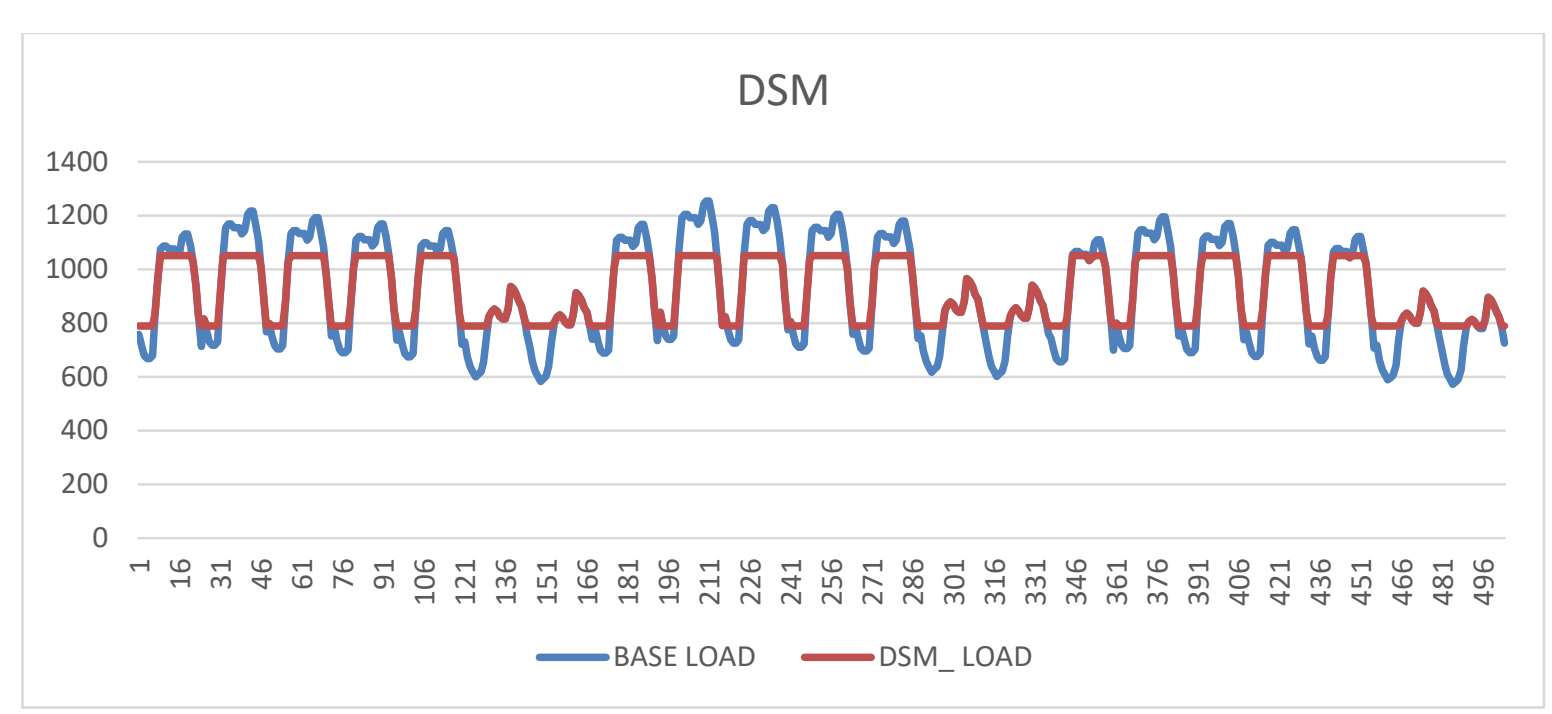

Figure 4. The three weeks DSM implementation on the chronological load model

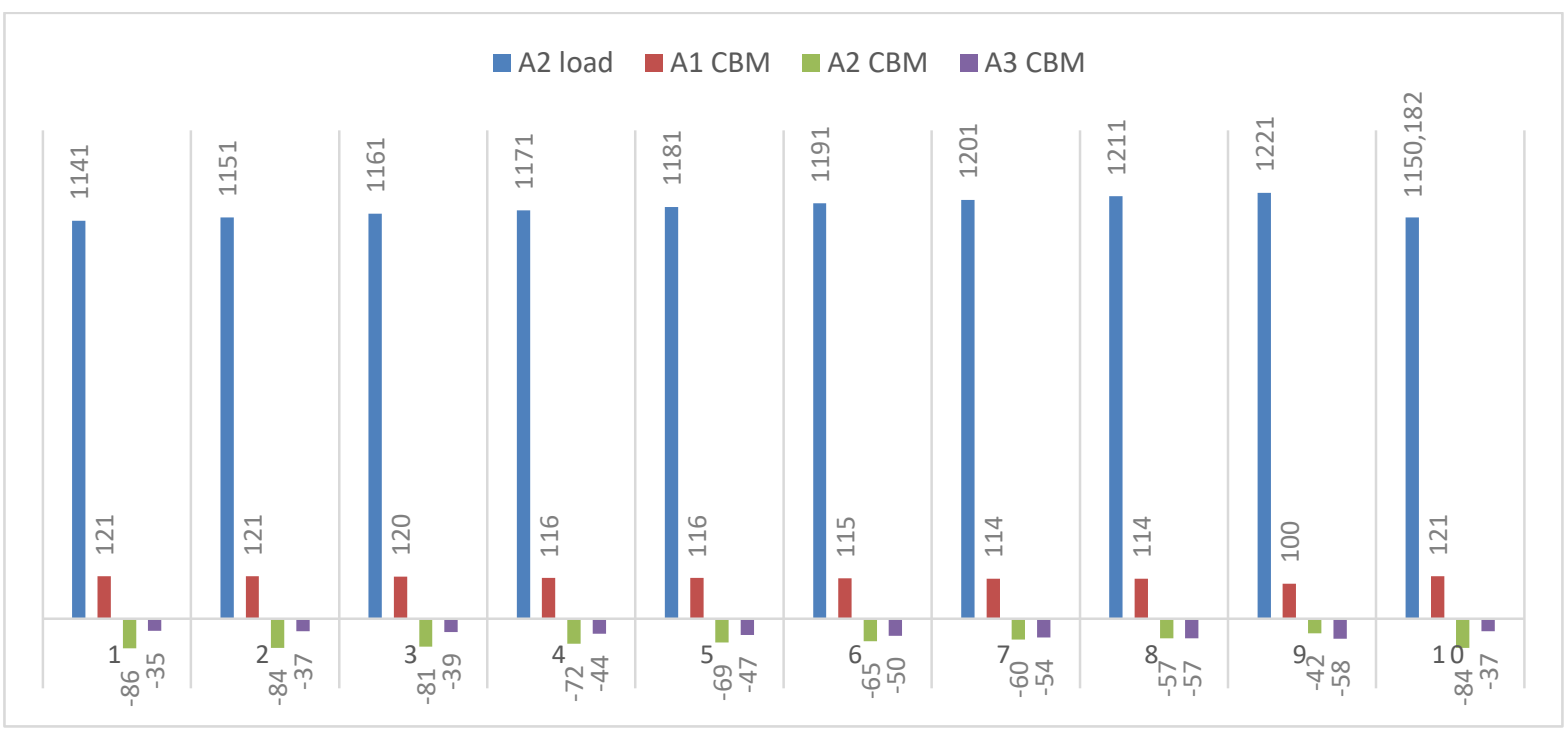

Figure 5. Effect DSM activities on interarea CBM

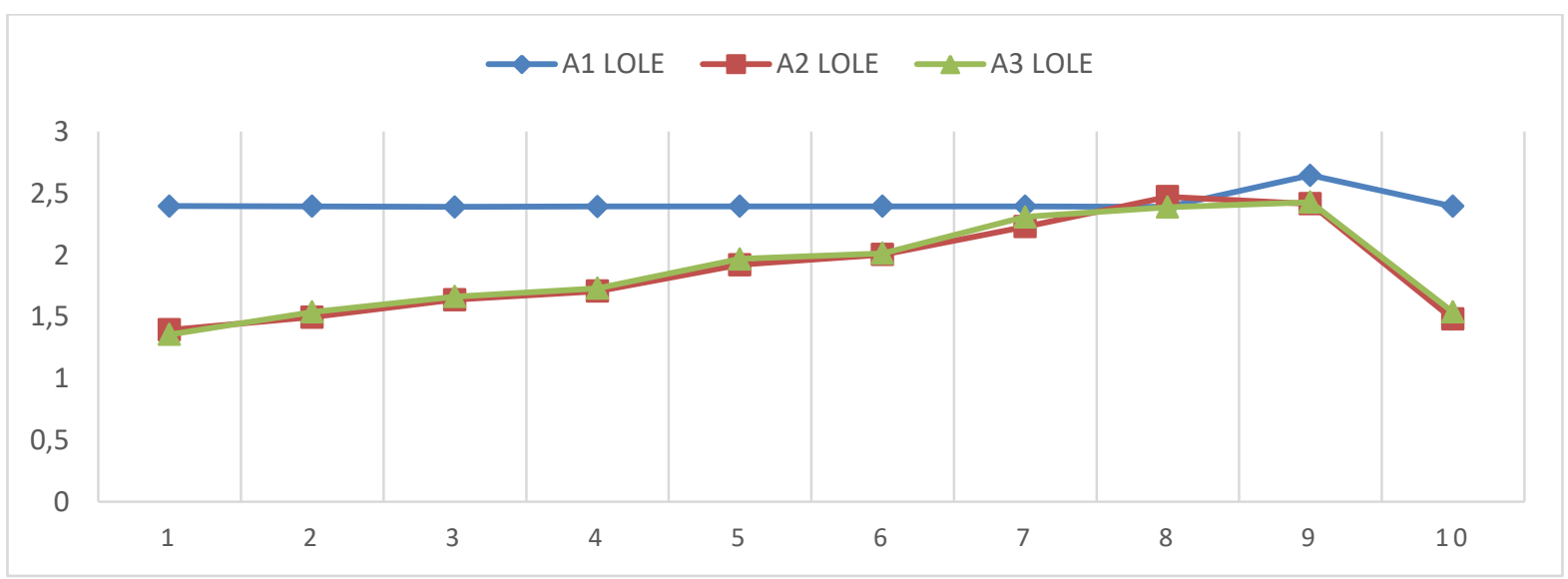

Figure 6. Effect DSM activities on the LOLE of areas 


\section{CONCLUSION}

This paper has presented a systematic approach to evaluating the influence of DSM resources on interarea CBM and LOLE as indices for generation reliability. The sensitivity of CBM and LOLE to load increase in A2 was investigated and the continuous increase in load in A2 results in LOLE and CBM degradation in all areas. The DSM resources are used to improve the generation reliability in a critical situation at which the CBM from A2 and A3 can no longer support A1. The contribution of this work is the assessment of the CBMs support from A2 and A3 at a critical condition, using the flexibility of DSM technique. This technique is beneficial economically to the utilities in strengthening the generation reliability, it improves the reserve capacity during on-peak periods. It also contributes to congestion management, as the heavy load in some part of the network can be reduced using load clipping actions of DSM, thereby lessen the stress on the system components. The algorithm for the proposed method is developed in MATLAB R2018a and Microsoft Excel 2013. IEEE 24-bus RTS is employed for the verification of the proposed technique. The results indicate that DSM activities, specifically peak clipping, have a remarkable contribution to CBM and LOLE improvement.

\section{ACKNOWLEDGEMENTS}

The remarkable technical support from Prof. M. W. Mustafa is highly appreciated. I would like to acknowledge the Universiti Teknologi Malaysia (UTM) for providing the facilities and enabling environment which is quite imperative to research activities. This research is funded by Research University Grant of Universiti Teknologi Malaysia, under Grant Number: Q.J130000.2523.17H10.

\section{REFERENCES}

[1] J. Zhu, Optimization of power system operation. John Wiley \& Sons, 2015.

[2] J. F. Smith, "Critical infrastructures at risk: Securing the European electric power system," ed: BERKELEY ELECTRONIC PRESS 2809 TELEGRAPH AVENUE, STE 202, BERKELEY, CA 94705 USA, 2008.

[3] P. Kundur et al., "Definition and classification of power system stability IEEE/CIGRE joint task force on stability terms and definitions,"in IEEE transactions on Power Systems, vol. 19, no. 3, pp. 1387-1401, Aug. 2004.

[4] S. C. Savulescu, "A metric for quantifying the risk of blackout," IEEE PES Power Systems Conference and Exposition, 2004., New York, NY, 2004, pp. 1661-1664 vol.3.

[5] O. O. Mohammed, M. W. Mustafa, D. S. S. Mohammed, and A. O. Otuoze, "Available transfer capability calculation methods: A comprehensive review," International Transactions on Electrical Energy Systems, Research Article 2019.

[6] M. Jacobs, "of the largest power outages in history-and what they tell us about the 2003 northeast blackout."," Union of Concerned Scientists, vol. 8, p. 2013.

[7] N. Rep, "Available transfer capability Definitions and determinations," North American Electric Reliability Council (NERC), 1996.

[8] I. Dobson et al., "Electric power transfer capability: concepts, applications, sensitivity and uncertainty," PSERC Publication, no. 01-34, 2001.

[9] Y. Ou and C. Singh, "Assessment of available transfer capability and margins," in IEEE Transactions on Power Systems, vol. 17, no. 2, pp. 463-468, May 2002.

[10] A. Gheorghe, M. Masera, M. Weijnen, and L. De Vries, "Critical infrastructures at risk," Securing the European electric power system, 2006.

[11] W. Li, "Reliability assessment of electric power systems using Monte Carlo methods". Springer Science \& Business Media, 2013.

[12] A. P. Ford and W. L. Harm, "Market based adequacy: reliability and CBM/ATC calculations. An independent system operator's perspective," 2002 IEEE Power Engineering Society Winter Meeting. Conference Proceedings (Cat. No.02CH37309), New York, NY, USA, 2002, pp. 18-23 vol.1.

[13] M. M. Othman, A. Mohamed, and A. Hussain, "Available transfer capability assessment using evolutionary programming based capacity benefit margin," International Journal of Electrical Power \& Energy Systems, vol. 28, no. 3, pp. 166-176, 2006.

[14] M. M. Othman, N. Abd Rahman, I. Musirin, M. Fotuhi-Firuzabad, and A. Rajabi-Ghahnavieh, "A Heuristic Ranking Approach on Capacity Benefit Margin Determination Using Pareto-Based Evolutionary Programming Technique," The Scientific World Journal, vol. 2015, 2015.

[15] R.-F. Sun, Y.-H. Song, and Y.-Z. Sun, "Capacity benefit margin assessment based on multi-area generation reliability exponential analytic model," IET generation, transmission \& distribution, vol. 2, no. 4, pp. 610-620, 2008.

[16] R. Rajathy, R. Gnanadass, K. Manivannan, and H. Kumar, "Computation of capacity benefit margin using differential evolution," International Journal of Computing Science and Mathematics, vol. 3, no. 3, pp. 275-287, 2010. 
[17] M. Ramezani, M. Haghifam, C. Singh, H. Seifi and M. P. Moghaddam, "Determination of Capacity Benefit Margin in Multiarea Power Systems Using Particle Swarm Optimization," in IEEE Transactions on Power Systems, vol. 24, no. 2, pp. 631-641, May 2009.

[18] M. Ramezani, H. Falaghi, and C. Singh, "Capacity benefit margin evaluation in multi-area power systems including wind power generation using particle swarm optimization," in Wind Power Systems: Springer, 2010, pp. 105-123.

[19] N. B. A. Rahman, M. M. Othman, I. Musirin, A. Mohamed and A. Hussain, "Capacity Benefit Margin (CBM) assessment incorporating tie-line reliability," 2010 4th International Power Engineering and Optimization Conference (PEOCO), Shah Alam, 2010, pp. 337-344.

[20] Y. Liu, J. Wang, L. Zhang, and D. Zou, "Research on Effect of Renewable Energy Power Generation on Available Transfer Capability," JSW, vol. 8, no. 4, pp. 802-808, 2013.

[21] T. Akbari, A. Rahimikian, and A. Kazemi, "A multi-stage stochastic transmission expansion planning method," Energy Conversion and Management, vol. 52, no. 8, pp. 2844-2853, 2011.

[22] H. Farahmand, M. Rashidinejad, A. Mousavi, A. Gharaveisi, M. Irving, and G. Taylor, "Hybrid mutation particle swarm optimisation method for available transfer capability enhancement," International Journal of Electrical Power \& Energy Systems, vol. 42, no. 1, pp. 240-249, 2012.

[23] R. Allan, "Reliability evaluation of power systems". Springer Science \& Business Media, 2013.

[24] H. Daryabad, "Investigating the Effect of Demand Side Management on the Power System Reliability," Bulletin of Electrical Engineering and Informatics, vol. 4, no. 2, pp. 96-102, 2015.

[25] Ming Zhou, Yajing Gao and Gengyin Li, "Study on improvement of available transfer capability by Demand Side Management," 2008 Third International Conference on Electric Utility Deregulation and Restructuring and Power Technologies, Nanjing, 2008, pp. 545-550.

[26] A. Malik, "Simulation of DSM resources as generating units in probabilistic production costing framework," in IEEE Transactions on Power Systems, vol. 13, no. 4, pp. 1528-1533, 1998.

[27] M. Fotuhi-Firuzabad and R. Billinton, "Impact of load management on composite system reliability evaluation short-term operating benefits," in IEEE Transactions on power systems, vol. 15, no. 2, pp. 858-864, 2000.

[28] R. T. Force, "The IEEE reliability test system-1996,"in IEEE Trans. Power Syst, vol. 14, no. 3, pp. 1010-1020, Aug. 1999.

[29] R. Billinton and R. N. Allan, "Reliability assessment of large electric power systems". Springer Science \& Business Media, 2012.

\section{BIOGRAPHIES OF AUTHORS}
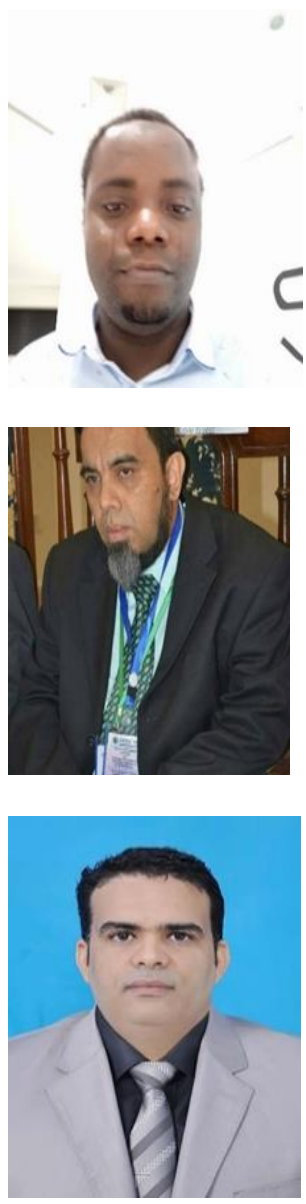

Olatunji Obalowu Mohammed received the B.Eng. degree in Electrical Engineering from Bayero University Kano, Kano State, Nigeria, and MSc in Electrical and Electronics Engineering from Coventry University, Coventry, UK in 2010 and 2014 respectively. He is currently a Ph.D. student at the School of Electrical Engineering, Universiti Teknologi Malaysia (UTM). He is also currently a Lecturer at the Department of Electrical and Electronics Engineering, University of Ilorin, Kwara State, Nigeria. He is a registered Engineer with Council for the regulation of engineering in Nigeria (COREN), Member of the Nigerian Society of Engineers (MNSE) and

C IEB EE member. His research area is on Energy efficiency, Demand side management, transfer capability assessment, sustainability and control of Renewable energy and distributed system.

Mohd Wazir Mustafa received his B. Eng. Degree (1988), M. Sc. (1993) and PhD (1997) from University of Strathclyde, Scotland, UK. He is currently a Professor and the Chair of the School of Electrical Engineering, Universiti Teknologi Malaysia. He is a member of Institution of Engineers, Malaysia (IEM) and a member of IEEE. His research interest includes power system stability, FACTS, wireless power transmission and power system distribution automation. He has published books, and has more than 300 publications in variouis Journals and conference proceedings.

A systematic approach to evaluating the influence of demand side... (Olatunji Obalowu Mohammed)

Daw Saleh Sasi Mohammed received his B. Eng. Degree (2004), M. Sc. (2010) and PhD (2017) in Electrical Engineering from the University of Sirte Libya, Universiti Teknologi Malaysia (UTM), Universiti Technologi Mara respectively (UiTM). He is currently a Lecturer at TMC college Kuala Lumpur, Malaysia. In June 2006 until November 2007, he held a position as the Head of Planning Department branch Sirte-Libya at the GECOL electric power utility. His research interests are in energy efficiency, demand side management, transfer capability assessment, reliability assessment and probabilistic study in power system. 


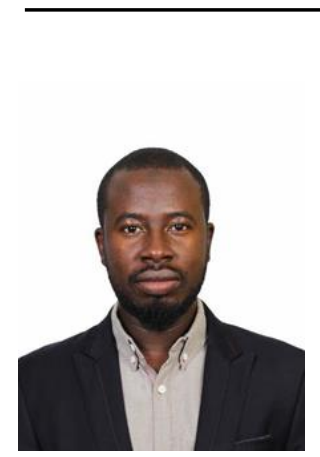

Sani Salisu received the B.Eng. degree from Ahmadu Bello University, Zaria, Kaduna State, Nigeria, and MSc in Renewable Energy Systems from Kingston University London, UK in 2010 and 2013 respectively. He is currently a Ph.D. student at the School of Electrical Engineering, Universiti Teknologi Malaysia (UTM). He is also currently a Lecturer at the Department of Electrical Engineering, Ahmadu Bello University, Zaria, Kaduna State, Nigeria. He is a registered Engineer with Council for the regulation of engineering in Nigeria (COREN), Member of the Nigerian Society of Engineers (MNSE) and IEEE student member. His research area is on Renewable energy and distributed system.

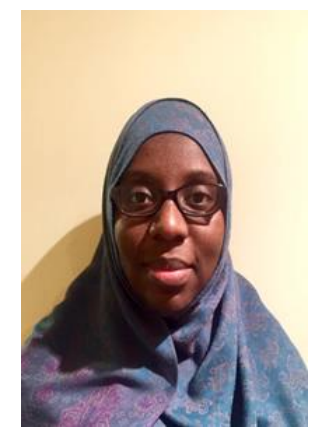

Nabila Ahmed Rufa'i received her B.Eng. degree in Electrical Engineering from Bayero University Kano, Kano State, Nigeria, and MSc. (Eng.) in Electrical Engineering and Renewable Energy Systems from the University of Leeds, Leeds, UK in 2010 and 2013 respectively. She is currently pursuing a $\mathrm{PhD}$ in Electronic and Electrical Engineering from the University of Leeds. She is also currently a Lecturer at the Department of Electrical Engineering, Bayero University Kano, Kano State, Nigeria. She is a member of the University of Leeds Institute of Communications and Power Networks (ICaPNet). Her research area is on Microgrid modelling and control in a weak grid. 